\title{
Which Countries and Industries Contributed the Most to the Decline in Trade Barriers Around the World?
}

Ana Maria Santacreu, Economist

Heting Zhu, Senior Research Associate

ince the 1980s, the world has become more globalized; that is, volumes of trade and financial flows around the world have been increasing consistently. ${ }^{1}$ Globalization has been characterized by a decline in trade barriers. In this essay, we explore which countries and industries have contributed the most to this globalization trend. To do that, we need a measure of trade barriers at the country and industry level. Although time series data on this measure are limited, Santacreu and Zhu (2018) infer trade barriers at the country and industry level from trade and production data for 42 countries and 20 industries for 2000-14.2,3 These frictions capture both geographic barriers (i.e., distance, common language, and border sharing) and policy barriers.

Diverse trends across countries and industries are behind the global decline in trade barriers.

Using these data, we examined trade barriers across all country pairs and industries and found that they declined during 2000-14. Figure 1 shows that the average trade barrier in the period declined by a sizable 45 percent.

Despite trade barriers having, on average, declined over time, there is substantial heterogeneity in our estimated barriers at the country-pair and industry levels. For instance, country pairs that generally have the lowest barriers in our sample include United States-Canada, Belgium-Netherlands, and Russia-Estonia. In each of these country pairs, countries are geographically closer to each other and share similar cultural values. In contrast, country pairs that have larger barriers are Australia-Slovakia, Czech Republic-United States, and Bulgaria-Canada. From an industry perspective, we find that trade barriers are largest for reproduction of recorded media; coke and refined petroleum products; and agriculture and mining. Trade barriers are smallest for electrical equipment; rubber and plastic products; and textiles, apparel, and leather. This ranking of globalization

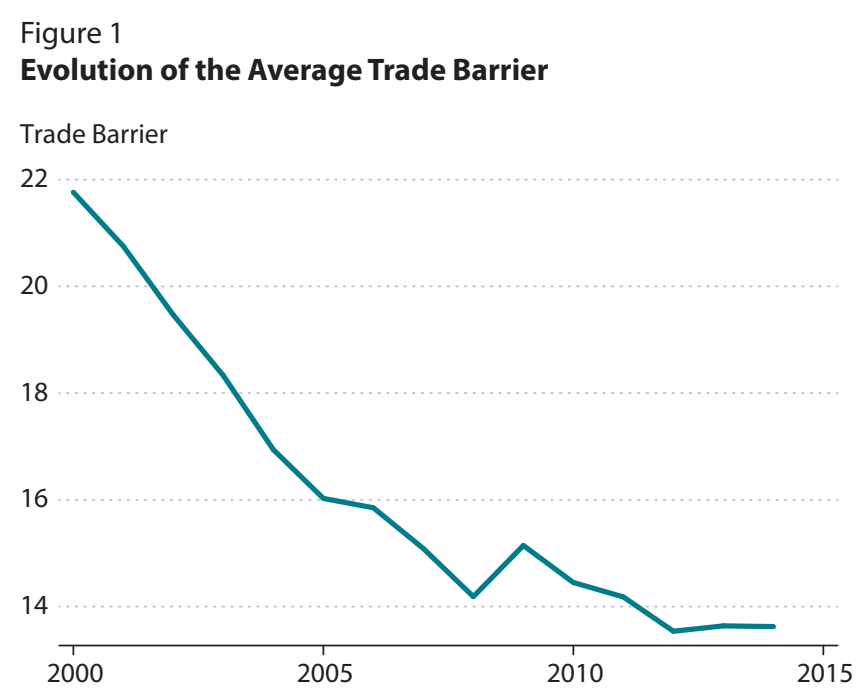

SOURCE: Authors' calculations. The average trade barrier reflects the amount of goods shipped for a buyer to receive one unit of a good.

across industries is preserved over time. (See Figure 2 for 2005 and 2012 data.)

Given this heterogeneity at the country-pair and industry levels, we explore which countries and industries have contributed the most to the average decline in trade barriers around the world. China appears to be one of the countries that experienced the largest decrease during 2000-14, whereas Switzerland is among the countries that experienced the smallest decrease (see the left panel of Figure 3). China unilaterally liberalized its trade even before being admitted to the World Trade Organization. According to an IMF report by Nicholas Lardy, China largely abandoned its centralization and economic planning for international trade in the late 1990s. Successfully joining the WTO in 2001 also helped China lower its trade barriers with other countries. ${ }^{4}$ Switzerland's trade barrier decrease was smaller than China's, but Switzerland's barrier was lower to begin with and remained lower than China's in 2014. Overall, trade liberalization has been improving across all countries.

We then investigate the evolution of trade barriers across industries. We find that the largest decrease in trade 
Figure 2

Trade Barriers by Industry, 2005 and 2012

Log of Trade Barrier

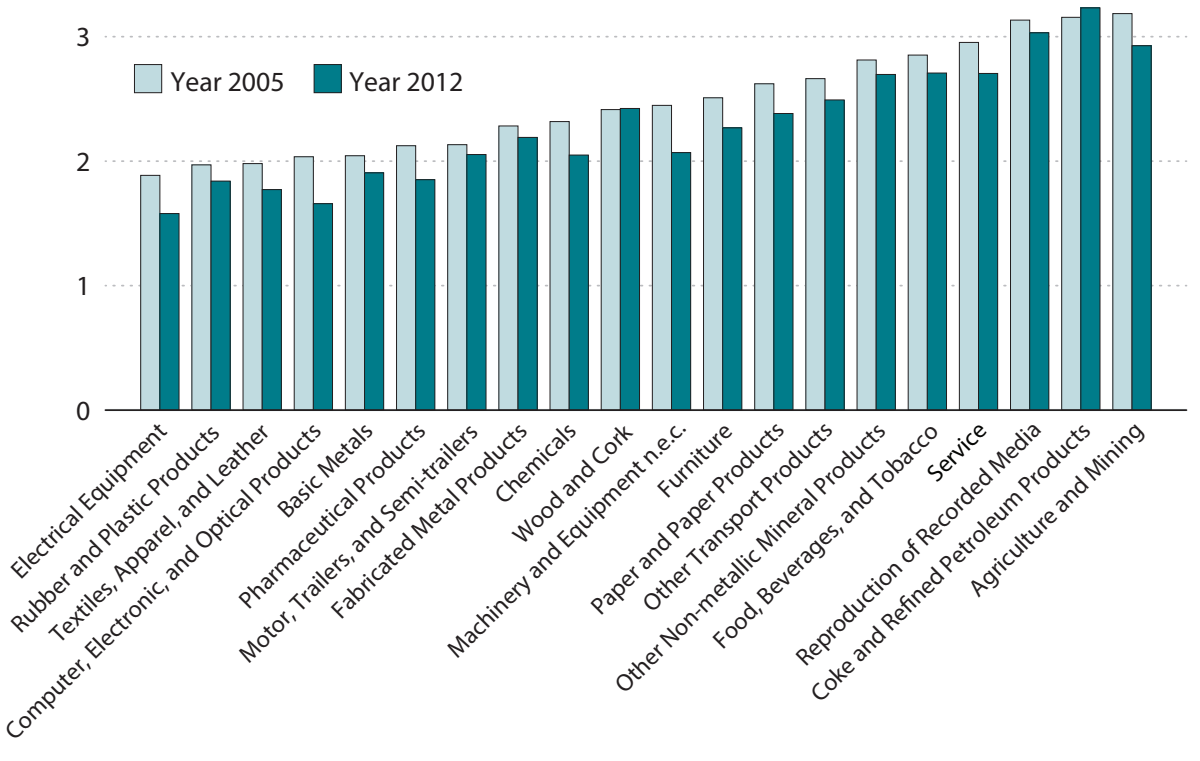

SOURCE: Authors' calculations.

\section{Figure 3}

Evolution of Trade Barriers by Exporting Countries and Industries

Trade Barrier

35

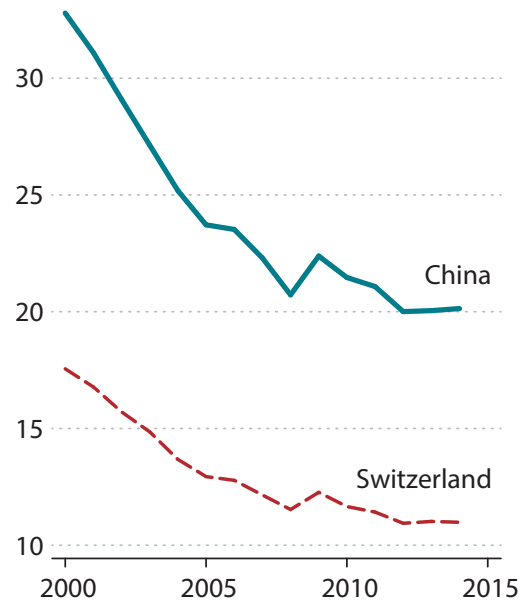

SOURCE: Authors' calculations.
Trade Barrier

25

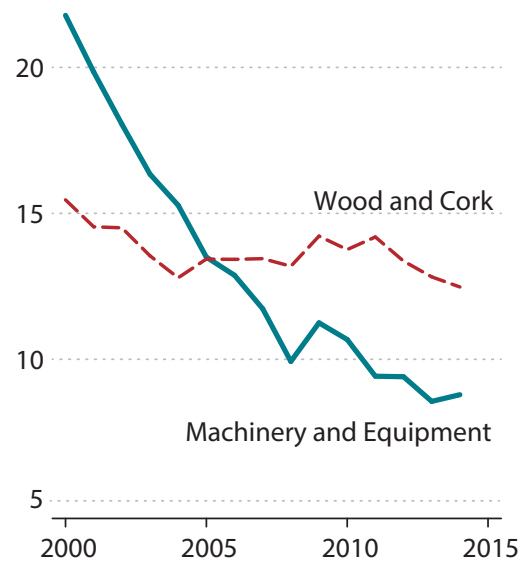

barriers came from the machinery and equipment industry, while the smallest decrease came from the wood and cork industry. The right panel of Figure 3 illustrates this substantial decline of trade barriers for machinery and equipment and relatively flat line for wood and cork.

In summary, we observe a persistent decline in trade barriers over the past two decades. Identifying which countries and industries are behind this decline may shed light on the relation between trade and productivity growth at the country and industry level. For instance, Cai, $\mathrm{Li}$, and Santacreu (2017) show that a decline in trade barriers has an effect on the R\&D efforts of a country, as it reallocates $\mathrm{R} \& \mathrm{D}$ spending toward those sectors in which the country has comparative advantage. ${ }^{5}$ Ultimately, these trends have an impact on the welfare effects of trade liberalizations. 


\section{ECONOMIC Synopses}

\section{Notes}

1 IMF Staff. "Globalization: A Brief Overview." International Monetary Fund, May 2008.

2 Santacreu, Ana Maria and Zhu, Heting. "Domestic Innovation and International Technology Diffusion as Sources of Comparative Advantage." Federal Reserve Bank of St. Louis Review, Early Edition 2018.

3 See Santacreu and Zhu (2018) for detailed country and industry lists.

4 Lardy, Nicholas. "Trade Liberalization and Its Role in Chinese Economic Growth." International Monetary Fund, November 2003.

${ }^{5}$ Cai, Jie; Li, Nan and Santacreu, Ana Maria. "Knowledge Diffusion, Trade and Innovation Across Countries and Sectors." Federal Reserve Bank of St. Louis. Working Paper 2017-029A. 